\title{
21. The Textbook in a Changing Multimodal Landscape
}

\begin{abstract}
In this chapter we explore communication and learning in the contemporary social world. Taking the textbook as a 'case study' we identify changes in multimodal text making - in the use of writing, image, layout and typography - and highlight their social pedagogic significance. The theoretical frame of our account is Social Semiotics. Drawing on a corpus of English, Science and Maths textbooks and digital learning resources published between 1930 and now we render visible profound shifts in the semiotic landscape of education. Teachers and designers of learning resources have always drawn on a range of different 'modes' - writing and image foremost among them, yet a combination of social change and new technologies has given rise to the possibilities for an increase in the use of more modes than these, in new 'ensembles' of modes, and with differently distributed functions. The chapter explores what the implications of these changes are for what and how students learn. We begin the chapter by outlining the aims and background of the study, our social semiotic theoretical framework and the data and methods used. Following that we discuss changes in the modes of writing, image, typography and layout in textbooks from different eras, and explore the use of moving and dynamic image and speech in online learning resources.
\end{abstract}

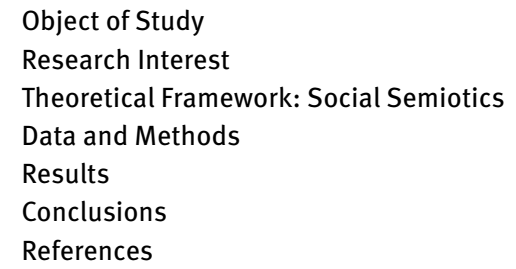

\section{Object of Study}

Contemporary school textbooks for secondary schools in England and elsewhere look radically different from their twentieth century predecessors. Their design has changed significantly: Image has become a central mode of representation, while frequently there is less writing. Colours have become abundant, captions optional. While images had featured in textbooks in that earlier period, now not only do there seem to be more images than before, they have also come to serve semiotic functions previously served by writing alone. 
These changes are illustrative of profound shifts in the semiotic landscape of education and beyond. Teachers and designers of learning resources have always drawn on a range of different 'modes' - writing and image foremost among them, yet a combination of social change and new technologies have given rise to the possibilities for an increase in the use of more modes than these, in new 'ensembles' of modes, and with differently distributed functions. For instance, diagrams, photographs, and drawings are now widely available through (online) picture banks and the cost of including them in textbooks is significantly lower than before. Parallel shifts can be observed in other domains. For instance, (young) people produce texts, on paper or on the screen, inside and outside school, using image, layout and typography as much as writing (Burn 2009; Mavers 2011; Yandell 2013).

The contemporary semiotic landscape is also shaped by the introduction of new means of dissemination. Some 'e-textbooks' can already be downloaded and read on a Kindle or other tablet, and excerpts can be projected onto an Interactive Whiteboard, alongside materials sourced from the web: A lesson in poetry now often begins with an image, where previously it began (and ended) with a poem (Jewitt et al. 2009). The screen has also prompted the development of entirely new - digital - learning platforms, involving a range of different 'authors', in which images are widely used, alongside modes of representation that the textbook does not afford, such as moving image and sound. Museums, for instance, have created online learning spaces where students can access videos and other resources related to exhibitions. Yet other platforms offer resources whose authors do not have the authority typically attached to museums, and do not include references to the National Curriculum, as museums in England often do.

Notwithstanding the rise of digital learning platforms, print-based textbooks are still widely used: The UK Publisher's Association have reported a 6 per cent increase in the sales of 'physical' school books in the UK in 2012, to £172m (PA 2013).

The notion of multimodality (Kress 2010) has become an essential means of describing these semiotic changes alongside a much wider range of modes of communication that teachers and learners draw on. Multimodal studies have shown how curriculum and pedagogy are articulated in the architecture of classrooms, in the embodied action of teacher and students and objects such as 3D artefacts (Kress et al. 2001; 2005), and a range of other semiotic resources. Recognizing the resources used by teachers and learners and their potentialities and constraints has become a key focus of our work (see also New London Group, 1996; Cope/Kalantzis 2009).

Semiotic changes in textbooks and contemporary learning environments more generally go hand-in-hand with profound social changes. Until some decades ago, 'textbooks' were produced in an era of relative stability; 'producers' - authors, graphic designers etc. - designed for audiences that were relatively fixed and known. Now, while 'imagined' abilities and age still act as official reference points, student populations are ever more diverse, socially and culturally, and, at the same time, have access to a much wider range of learning environments and resources than before, 
both inside and outside school. Where until, say, the early 1990s the textbook was a dominant and uncontested 'learning platform' for students in the Western world, they now have immediate access to resources on digital learning platforms, which they can access through different (mobile) devices.

One effect of the availability and accessibility of more and different (digital) learning platforms is the changing relation between 'producers' and 'users' of textbooks, between those responsible for the 'curriculum', and those engaging with the resources designed to help 'reproduce' that curriculum. As 'users' of textbooks now engage with a wide range of different resources as for instance videos, apps, wikis, which are produced by different groups of 'authors' such as educational publishers, museums, anonymous authors, entirely new forms of engagement emerge through smartphones and tablets. 'Readers' now create reading paths across different learning platforms, doing much of the ordering, selection, navigation and production of cohesion that was previously done by textbook producers and teachers alone. That has far-reaching implications for what and how students learn.

\section{Research Interest}

Our interest was and is in the social-pedagogic significance of changes in texts, through the use of image, writing and others modes, and their now often different relations; and in the ways in which the social is instantiated in the fine grain of multimodal texts more generally. Taking the textbook as a 'case study' of changes in multimodal text making, we aim to gain a better understanding of communication and learning in the contemporary world.

The social and semiotic changes we have just sketched prompt three major questions. First, what exactly is it that has changed in the multimodal design of textbooks for secondary school students over the last century? What shifts in the use of image, writing, layout, colour, and other modes of representation can be observed? Is image indeed becoming central in textbooks? Second, what is it that may have been gained and what may have been lost in potentials for learning as a result of these changes? Are the changes in design leading to intended or unintended consequences in what and how students can and will learn, or to changes in their control over what and how they learn? Third, does the changing position of the textbook as one among many different learning platforms match the observed changes in design?

In a study funded by the Economic and Social Research Council (Gains and Losses: Changes in Representation, Knowledge and Pedagogy in Learning Resources, RES-06223-0224), carried out in the period between 2007 and 2009 we looked at (packages of) materials produced by publishers in England and Wales, mediated through pages or screens, representing 'curricular knowledge' and intended to be used as resources for 
learning at school or at home. We looked at the core subjects of the National Curriculum for England and Wales, that is, English, Science and Mathematics.

We focused on three periods of time that seemed distinctive; we call them, somewhat overblown, 'eras'. The first period, 1930-1940, represents the era in which the constellation of the medium of the book and the mode of writing was central, stable and taken for granted (Stray 1994). The second period, 1980-1990, is taken to represent the era in which the book was still the dominant medium, while modes other than writing, notably image, gained significance (Unsworth 2001). The third, contemporary period, 1995-2005, is the era in which a shift has taken place towards a dominance of the medium of the screen rather than the book and digital 'learning platforms', while the mode of image has gained centrality (Jewitt 2006).

\section{Theoretical Framework: Social Semiotics}

The theoretical frame of our account of changes in the textbook is Social Semiotics. A social semiotic approach to text places multimodality and agency in meaning making at the centre of attention (Bezemer/Kress 2008). It ascribes meaning to all modes of communication, including image, writing, typography and layout; and it treats signs of any kind as reflecting the interests of the makers of these signs - here, curriculum planners, textbook designers, teachers. In each of the modes used, semiotic work attending, engaging, transforming, integrating, ordering - is done by both makers and users of textbooks. In one mode more semiotic work is to be done by the reader (the layout of a modular text, say), in another, simultaneously present mode, more work has been done for the reader by the designer (in continuous segments of writing, say). Text design is based on such 'division of labour', and only by looking at the entire, multimodal design can we reconstruct these complex social relations.

Producers are regarded as sign-makers as are users-as-interpreters of text, and, in that, both are seen as meaning-makers. Signs are elements in which meaning and form have been brought together in a relation motivated by the interest of the signmaker. A sign made by a textbook 'producer'/'maker'/'designer' is re-made ('interpreted') by a 'user'/'reader' (who may or may not represent the imagined audience of the textbook maker). Sign-making is always subject to the availability of semiotic resources and to the aptness of the resources to the meanings which the sign-maker wishes to realize. In principle, limitations of resources apply always and everywhere, even if not with the same severity: in many classrooms around the world there exist the severest constraints on resources both for teachers and children. Nevertheless, the design of a text is treated by us as the sign-maker's apt representation of her or his interest, given the resources available in the circumstances which prevail. This means that the signs made by the textbook 'makers' are never exact replicas when they are re-made by their 'users'. This points to a significant difference between our 
social semiotic theory of communication and theories which assume that 'messages' are 'encoded', 'transferred' and then 'decoded'.

The interest of the producer of the texts at issue here is pedagogical. Pedagogical interest responds to questions such as, What is my preferred social relation with my imagined audience and how can I best realise it? How is the subject content best shaped and realized to represent my theoretical conception of the subject while maximising the learner's engagement? The producer's as well as the audience's interests are shaped by the social, cultural, economic, political and technological environments in which signs are made; the design is the result of the interaction between all of these. At the same time sign-makers have to be aware of the media of distribution for their signs - now often spoken of as 'platforms', especially in the case of digital environments - and that awareness is factored into the making of the sign.

Signs are made using the resources of modes. Our notion of mode is broadly in line with Klug/Stöckl's (2015, 243-247), with some differences. To us, a mode is a set of socially and culturally shaped resources for making meaning. Modes can be used to represent what the world is like, how people are socially related and how semiotic entities are connected (Kress 2014). Image, writing, layout, colour and typography are examples of modes used in (contemporary) textbooks. Modes offer differing representational resources. Writing for instance, has syntactic, grammatical and lexical as well as typographical resources such as type size, font and letter fit. Speech and writing share certain aspects of grammar, syntax and lexis. Beyond these, speech has resources of intonation for instance, of loudness, length, tone of voice. Image has resources such as pictorial detail, size, colour, and shape. These different resources can be used to do different kinds of semiotic work; or to do broadly similar semiotic work through the differential use of (elements of) resources. Modes, that is, have different material bases, which have been shaped, over time, in their social uses to 'mean'. This enables sign-makers to do different semiotic work in relation to their interests and their rhetorical intentions for designs of meaning; which, in modal ensembles, best meet the rhetor's interest and sense of the needs of the audience. That is, by drawing on the specific affordances of each mode in the making of complex signs as modal ensembles, sign-makers can achieve the complex, often contradictory demands of their own interest, of the needs of the matter to be communicated and of characteristics of the audience.

Given the complex relation of modal affordances, rhetor's interest and the variability and complexity of social environments, design moves into the centre of attention. We use the term 'designer' metonymically to refer to all those involved in the production of the textbook. In each of the modes semiotic work is done by the makers of the text, including authors, illustrators and graphic designers, as by the users of the text, including - in the case of textbooks - 'learners' and 'teachers'. The multiplicity of modes offers the designers a potential multiplicity of epistemological positions; the multimodality of textbook-design allows textbook makers to 'mix' different theories of learning in one text: in one mode the semiotic work to be done may draw 
more upon the learner, while in another, simultaneously operating mode, more work may be done for the reader by the textbook maker. In other words, one mode (writing, say, in the genre of procedure) may suggest a 'transmission' model of teaching and learning, another mode (image, say, in the genre of concept map) may suggest 'collaboration' and a 'constructivist' conception of learning and teaching; one may suggest learning based on induction, the other mode may suggest learning based on deduction. We can often see a mixture of such models of learning articulated within one and the same textbook. These mixtures may be deliberate attempts to synthesize different notions of learning for an increasingly diverse audience. They may also be the outcome of a less than carefully concerted effort to produce textbooks based on a shared understanding of learning.

\section{Data and Methods}

We reviewed 92 excerpts from 59 textbooks for English, Science and Mathematics, published in the 1930s, 1980s and 2000s, totalling 700 pages. These were randomly chosen from card and electronic catalogues of the library of the Institute of Education, University of London, the largest collection of textbooks in England. For reasons of comparability, each subject was represented by a 'stable' curricular issue across that period. In English, this was Poetry, in Science Digestion and Electric circuits, in Mathematics Angles and Fractions. We indexed, digitized and archived all excerpts as PDF-documents to enhance our analysis. Table 1 details the number of textbooks, textbook excerpts and pages in the data set by subject.

Table 1: Data set by number of textbooks, excerpts and pages

\begin{tabular}{llll}
\hline $\mathbf{N}$ & Textbooks & Excerpts & Pages \\
\hline English & 23 & 29 & 240 \\
\hline Science & 19 & 31 & 276 \\
\hline Mathematics & 17 & 32 & 187 \\
\hline Total & 59 & 92 & 703 \\
\hline
\end{tabular}

For each combination of 'era' (1930s, 1980s, 2000s) and subject (English, Science, Mathematics) we made an initial selection of 8 to 12 excerpts. We derived four subsets from the corpus, covering image-representations of the digestive system and of electric circuits, poems, and angles. Informally, we also collected 6 textbooks for secondary education from Germany, the Netherlands, Hong Kong, Japan and Brazil. We reviewed 16 digital learning resources, addressing topics from the National Curriculum for English, Science and Mathematics. For the purposes of this chapter, we also 
looked at materials produced between 2010-2014, including apps for i-pad, videos on Youtube, and a newly published Science textbook (Askey et al. 2014).

We developed an analytical framework in which Social Semiotics provides an overall integrating theory, and analytic means for the description and analysis of image, writing, typography and layout. It assumes that conditions for learning are shaped by every sign in every mode operating in a textbook. For image, we drew a distinction between photography and drawing; we attended to the 'provenance' of the images; and we analysed 'contextualisation', 'colour', 'pictorial detail', 'illumination', 'depth' and 'movement' (Kress/van Leeuwen 2006). We attended to the 'status relations' between image and writing, drawing on Barthes (1977) and Martinec/Salway (2005). For writing we looked at mood and clause relations, drawing on Halliday (1985) and Hodge/Kress (1988). For typography, we drew on Stöckl's (2005) 'toolkit' for analyzing type and resources such as spacing, orientation, indentation and typographic emphasis. Lastly, we focused on the layout of pages: attending to page format and grid, number of columns per page, column width, and orientation and alignment of page elements (Ambrose/Harris 2005; Haslam 2006). For speech, we focused on mood, clause relations and the use of intonation (Halliday 1967). Where it seemed appropriate, we counted the occurrences of certain modal realizations in texts across the three eras, to establish whether the use of a mode had changed diachronically or whether we were dealing with synchronic variation.

\section{Results}

\subsection{Changes in Design}

\subsubsection{Writing}

Consider the following excerpts of writing from science textbooks. In each, 'series' and 'parallel circuits' are compared.

\section{Excerpt 1 (Field 1937, 59).}

If two cells are joined together negative pole to positive pole, the circuit wires being taken from the free + and - terminals, they are said to be joined in series. In this arrangement of cells the total E.M.F. is the sum of that of the cells that are joined together. Thus, with the two dry cells the total E.M.F. would be nearly 3 volts. If, however, the two cells were joined positives together and negatives together, the circuit leads being taken one from the joined positives and the other from the joined negatives, the total E.M.F. would still only be that of one cell, although the battery of two cells could give nearly twice as much current. In this arrangement the cells are said to be joined in parallel. In all the batteries we have studied and used the cells have been joined in series. A third method of joining the three cells would be to join two positives or two negati- 
ves together, and then take the circuit leads from the two remaining identical terminals. This method would produce no E.M.F. and no current, for the two cells would be in opposition. These three possibilities are shown in Fig. 41. In this figure we again use the diagrammatic method of showing cells; two parallel lines. The longer, thinner line represents the positive terminal, the shorter thicker one the negative terminal.

\section{Excerpt 2 (Hill/Holman 1986, 104-105)}

All the circuits that we have looked at so far have been connected in series. In a series circuit, there is only one route for the current, because there are no junctions. Look closely at the circuit diagram in Figure 10.1 which contains two bulbs and three ammeters in series. When the circuit is complete, all three ammeters show the same reading, 0.2 amperes. This is because the current is the same at all points in a series circuit. Electrons leaving the negative side of the battery pass through each section of the circuit at the same rate, so the current is the same at all points. Figure 10.2 shows a circuit in which the bulbs are not connected in series. In this case, each bulb is connected singly across the battery. There are junctions in the circuit and more than one way for the current to flow round it. This time the bulbs are said to be connected in parallel.

\section{Excerpt 3 (Chapman/Sheehan 2003, 106)}

\section{Series circuits}

In series circuits the lamps are arranged side by side in the same loop as shown here. The more lamps there are, the more the current is slowed down through the whole circuit. The lamps shine less brightly than if there was only one lamp.

\section{Parallel circuits}

You can connect several lamps to the same size cell but keep them as bright as just one would be. You can put them in different loops. Look at the diagram on the right. This is called a parallel circuit. The diagram shows the current in a parallel circuit. The current branches off and goes through the two bulbs at the same time, not one after another. So, the current is not slowed down twice.

We can describe some of the differences between these three excerpts in terms of sentence structure, mood, voice and argumentation. In the excerpt from Field (1937) (11 sentences), the average number of clauses per sentence is 3.2, with a high of 7 clauses per sentence. The types of clause-relation within sentences are a mixture of paratactic relations - that is, clauses as relatively equal, much as beads in a chain; and of hypotactic relations, unequal relations, hierarchical, with relations of super- and subordinate. The form of argumentation in the paragraph is predominantly hypothetical and conditional: the genre is that of 'scientific hypothesis'. Image is mentioned at the end only; as a kind of visual 'underpinning' of an argument already made verbally. Writing is clearly 'prior', as the significant mode. If we were interested in the issue of 'scientificness' and of 'scientific writing', we might mention the frequency, dominance even, of agentless passives; in the 11 sentences there are 12 passive clauses: are joined together, wires being taken, they are said, joined in series, are joined together, 
were joined, leads being taken, the joined positives, the joined negative, are said, joined in parallel, joined in series.

In the 10 sentences in the excerpt from Hill/Holman (1986), the average number of clauses per sentence is 2 . There is one sentence with 3 clauses. The clause relations within sentences tend to be a mix of paratactic and hypotactic; the form of 'argumentation' is 'factual' rather than 'hypothetical'. The genre is that of report; though a report with an imperative form in it. There are six references to images: with an initial framing reference; an instruction/command to "look closely at the circuit diagram", a further reference to an image for comparison and conclusion. In the 10 sentences there are 5 agentless passives: connected in series, not connected in series, is connected singly, are said, connected in parallel. Compared to the excerpt from the 1930s, writing has become syntactically simpler. The 'address' of the reader through the genre of report rather than that of scientific hypothesis is different. Gone are hypotheticals and conditionals.

The written text-element from Chapman/Sheehan (2003) (10 sentences) has 'headings' as a means of subdividing the conceptual/textual material. For the ten sentences, the average number of clauses per sentence now is 1.7; with a high of 3 clauses in one sentence. The dominant form of clause connection is paratactic (with, possibly, depending on one's theory of grammar, two instances of hypotaxis). In this written piece of text, there is direct address of the reader: in the command "look at", and the slightly implicit command (twice) "you can”. The form of 'argumentation' is factual; the genre is a mix of instruction and report: declarative sentences dominate. There is one agentless passive clause. There are six, possibly seven, references to images, with an initial framing "as shown here" and the command "look at"; and a concluding/ ratifying "the diagram shows".

We can now make some instructive comparisons of the changes in written elements (and these are similar to changes in writing in English textbooks, cf. Bezemer/ Kress 2009):

1) the written elements contain fewer complex sentences, an effect both of a significant decrease in the number of clauses per sentence and of the decline of hypotaxis;

2) while the passive sentence form is still used as an indicator of scientificness the texts have moved to more frequent use of active voice in clauses;

3) the genre changes from the scientific hypothesis via the report to a mix of instruction and report;

4) there is a shift from the hypothetical to the factual and instructional.

All of these are indicators of changes in 'recontextualization' (Bernstein 1996). We might put it like this: the laboratory and its practices and forms recede more and more in a recontextualization which emphasizes the pedagogic and curricular tasks and characteristics of the contemporary conception of the school-subject Science. In the 1930s the 'author' ordered propositions in writing, one means of producing a coherent 
text-as-knowledge. Now, much of the work of producing structural relations between textual elements and, in that, of producing knowledge, is done by others. As we will discuss below, some of this semiotic work is now done through choices of layout and image by graphic designers and picture editors, and some is now in the hands of 'readers'.

\subsubsection{Image}

In order to produce some numerical evidence for our claim that 'there are more images now than before' we have attempted to count the number of images in all our textbook excerpts. The outcomes are perhaps unsurprising: the number of images in textbooks for English have increased significantly, from an average of virtually no images at all (0.03 images per page) in the1930s to one in every two pages (0.54 images per page) in 1980s, to three in every four pages (0.74 images per page) in the 2000s. Compared to subjects like Science and Mathematics, this number is still rather low, but it is by far the biggest increase for those three subjects: between 1930 and now, images in Science went up from 0.64 to 3.37 images per page, and in Maths they went up from 2.95 to 8.71 .

Not only are there more images now, their relation to other entities in the text has also changed. Take figures 1-2, from Science textbooks published in 1935 (Figure 1) and 2002 (Figure 2). The 1935 textbook uses both image and writing to introduce the main organs involved in digestion ("The pharynx and upper part of the gullet are in the neck...The oesophagus is a narrow muscular tube.”). In the contemporary learning resources, the organs are introduced solely through image. The image has brief captions but no commentary as in the 1935 book. The examples suggest a shift from a former design in which image illustrates an exhaustively detailed written account, to the present, where a constellation of image and writing serves complementary functions. In the 2002 example, image depicts the objects (organs) involved in digestion, while writing describes the processes (breakdown of food) involved in digestion. 
CHAPTER XVIII

ANIMAL NUTRITION: NUTRTTION IN THE MAMMAL

Introduction-In the Biology section of Part II we studied the structure of some simple animals and plants, and their life processes, i.e. how they obtain and uso food, bow they move, respire, excrete, and reproduce. In the present section we shall consider the structure and life processes of some higher animals and plantes.

How Food is Used-We have already studied the chief foodctuffs (p. 156). They are the useful constituenta of various substances used as food.

Food is used for two purposes within the body of an organism. It supplies energy, including heat, and it supplies substances which the living organism builds up into protoplasm. An organism needs energy because its active tissues expend energy. Some food-stuffs supply this energy. Aotive tissues also " wear away " and must be replaced. Growing organisms make additional tissue. New tissue, whether to replace waste or for growth, is made from certain food-stuffs which are built up into protoplasm.

Carbahysirates (p. 156) are the main source of energy, Pats (p. 158) supply heat. Proteins (p. 157), salts, and toater are used in making protoplasm. Respiration is the process by which food sets free enengy in the body of an organism. This will be otudied in the gext enopter. Notrition includes the

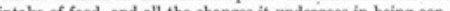
intakk of fod, a certed in of proploper aninals which are chased as

Mammals - A Mammal is a backboned animal (Vertebrate). Its young are born alive: they do not "hatch" from eggs. They are suckled by the mother, who produces milk for this purpos. digits, and its body in moro or loses elothed with hair.
Animal Nutrition: Nutrition in Mammal 161 Digestion is the first stage of nutrition. It takes place in the alimentary canal. We shall now consider this process in detail.

The Alimentary Canal (fig. 148).

Food taken in at the mouth passes into and along a tube called the alimentary canol, the other end of which opens at

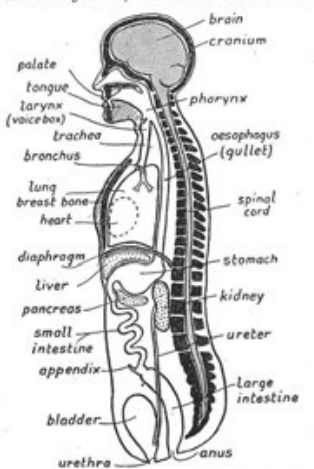

Fvo. 168-Chief internal organs of Man (nimple sochemo)

the hind end of the body. The opening is the anss. From the mouth onwards the parts of the alimentary canal are the " baek of the month" (pherymx), the gullet (arephegus), the "back of the mouth" (pharynx), the gullet (atophaguss), the eluding the mouth cavity, is lined with a soft pink tissue

Fig. 1: Excerpt from Science textbook (Fairbrother/Nightingale/Wyeth 1935, 161-162)

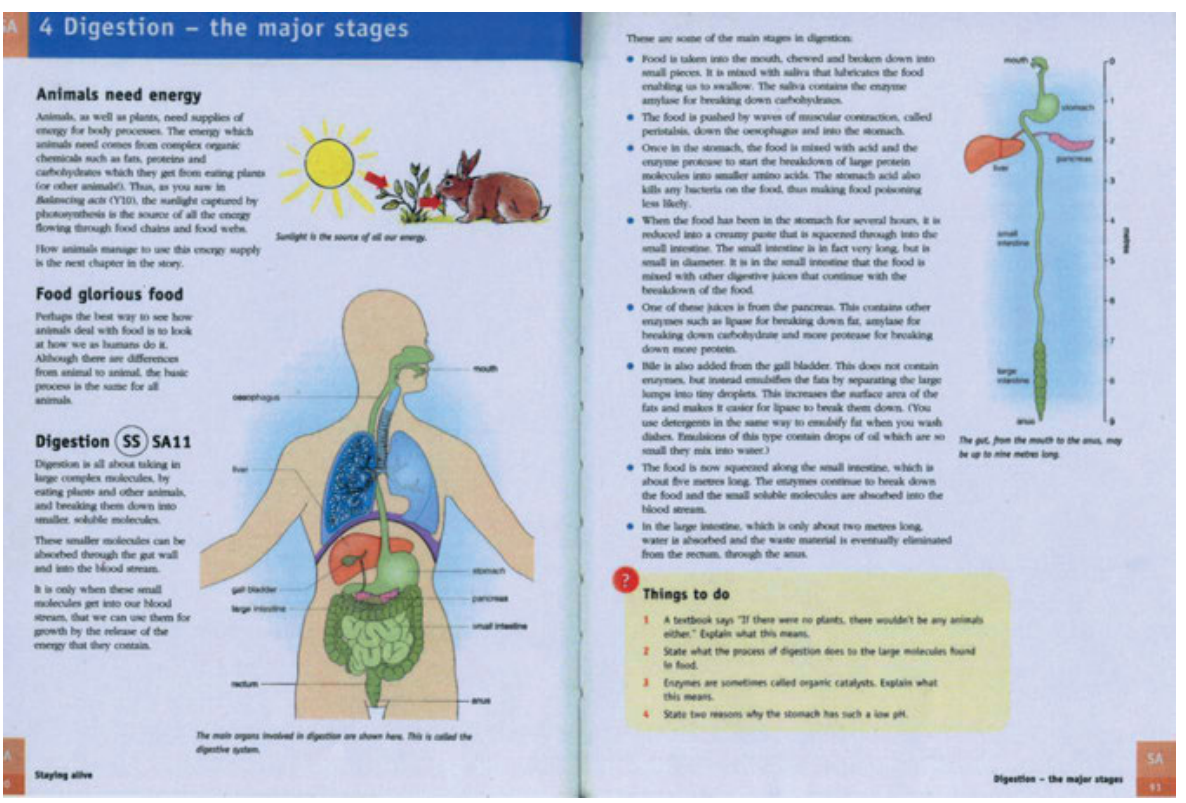

Fig. 2: Excerpt from Science textbook (Science Education Group 2002, 90-91) 
The question that arises from observations like these is: Do such changes in design make a difference to what and how students learn? Where writing is used as the dominant mode, it might be argued that the student's engagement with the text is organized by the logic of sequence in time. In writing, as in speech, something has to be mentioned first, something else second; and meaning attaches to being first and last, etc. In the 1930s textbook, the sentence "From the mouth onwards the parts of the alimentary canal are the 'back of the mouth' (pharynx), the gullet (oesophagus), the stomach, and the gut (intestine)" precedes the sentence "The pharynx and upper part of the gullet are in the neck" and this is the 'logical' order which readers are expected to follow in their attempts to make sense of the digestive system.

By contrast, where image is used, a different 'logic' seems to operate: the organs involved in the digestive system are not introduced in sequence. Rather, in the image all the organs are simultaneously present. Hence the drawing does not specify the reading path as writing does: learners can decide for themselves what to attend to and in which order to do so.

The logic of image has other implications for designers and learners as well. In drawing, designers are prompted to show the relative position and size of the oesophagus, while in writing they can but need not do so: they can refer to the oesophagus without detailing its spatial features. Where the author described these features, as in "the oesophagus is a narrow tube", the account is far less specific than the drawing, demanding different semiotic work from the learner. A shift from writing to image therefore has significant implications for what does and what does not become available for students to learn with. Additionally, it has implications for the order in which these potentials become available.

To summarize our observations so far: writing has changed, there are more images, and these images now often complement writing, instead of illustrating it. In Science textbooks, the images that complement writing are mostly diagrams, for instance, of anatomical structures, biological processes or electric circuits. Images that illustrate writing frequently place scientific categories introduced in writing in 'everyday' contexts; for instance, a photograph of someone taking a bite of an apple or hamburger is placed in the margin of a text on digestion. In textbooks of English, images are often used to illustrate aspects of a poem. Overall, the share of images 'illustrating' is still greater than the share of images 'complementing' - yet compared to textbooks from the 1930s, the ratio has shifted decisively towards more complementarity of image and writing.

Our next couple of examples illustrate one possible direction that future textbook designers might take: a design in which image is prior. The first of these is from a Japanese science textbook published in 2008 (Shoseki Books 2008), presented here as figure 3. 


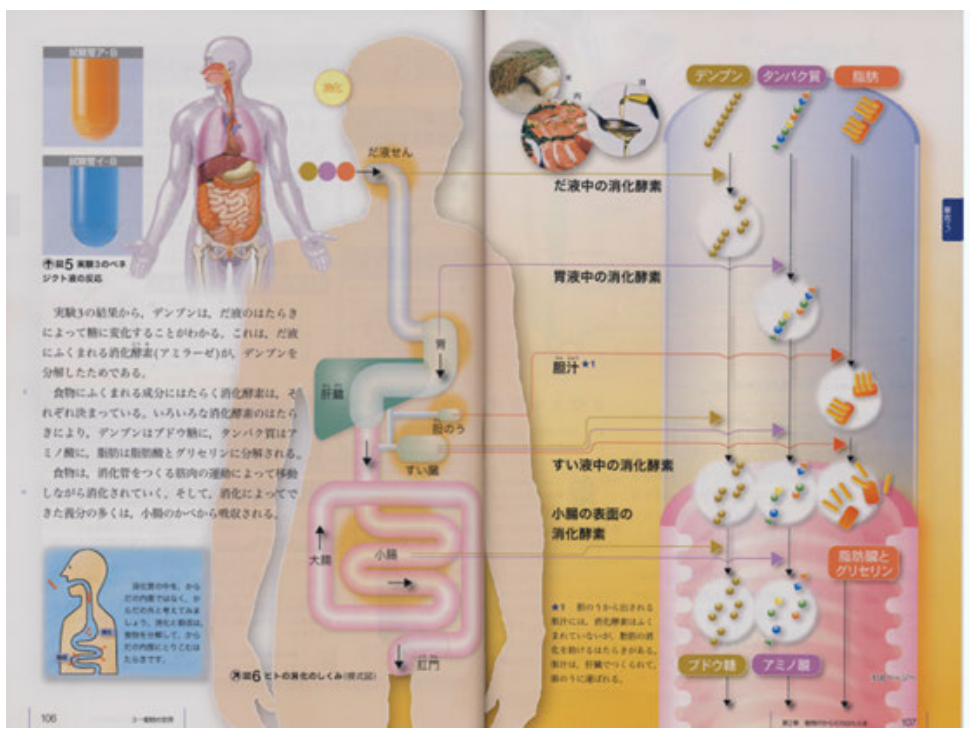

Fig. 3: Excerpt from Japaense Science textbook (Shoseki Books 2008, 106-107)

In the English Science textbook in figure 2 image only covers a relatively small part of the two-page spread; writing takes more space. In the Japanese textbook image covers the entire two-page spread, running across the pages; writing only features in a couple of relatively small areas, and it is superimposed onto image. The functional distribution of modes is also different. In the English Science textbook image is used to depict the size, shape and relative position of organs involved in digestion; writing is used to name these organs, and to describe the processes involved in digestion. In the Japanese textbook, image is used to depict the human body and the process of digestion. Some other English textbooks we reviewed do also use diagrams for processes, for instance to show how enzymes help breaking down food; yet in this Japanese example objects and processes, image and writing are entirely integrated, producing a single account of digestion.

\subsubsection{Layout}

While we did not find an equivalent of the spread from the Japanese Science textbook in English Science textbooks we did find a (slightly atypical) example of a more integrated design in which image is dominant in a textbook on English literature (Brindle/ Machin/Thomas 2002), presented here as figure 5. To explore this in more detail we lay it next to an excerpt from another English textbook (Mamour 1934), presented here as figure 4 . 
LESSON NINE

LITERATURE

'LALLugo.'

The Elizabethan age was succeeded by a period of religious and political strife, which culminated in the triumph of Puritanism under Oliver Cromwell. Therefore the expansive development of literature was restricted, and thought mainly concentrated on one particular book-the Bible. The dominating figure of this age is John Milton, the great Puritan poet; but he is so supremcly an artist that he blends the perfection of ancient art, as learnt from the Renaisance, with the religious turmoil of his time, which has had so profound an effect on his work. His most famous had so profound poem is the epic Poradise Lost, which relates the story of shorter poems, of which the following is an example.

$$
\text { L'ALLEORO }
$$

Haste thee, Nymph, and bring with thee Jest, and youthful jollity,

Quips, and cranks, and wanton wiles,

Nods, and becks and wreathéd smiles,

Sport that wrinkled Care derides,

And Laughter holding both his sides.

Come, and trip it as you go,

On the light fantastic toc:

And in thy right hand lead with thee
Fig. 4: Excerpt from English textbook (Mamour 1934, 85)

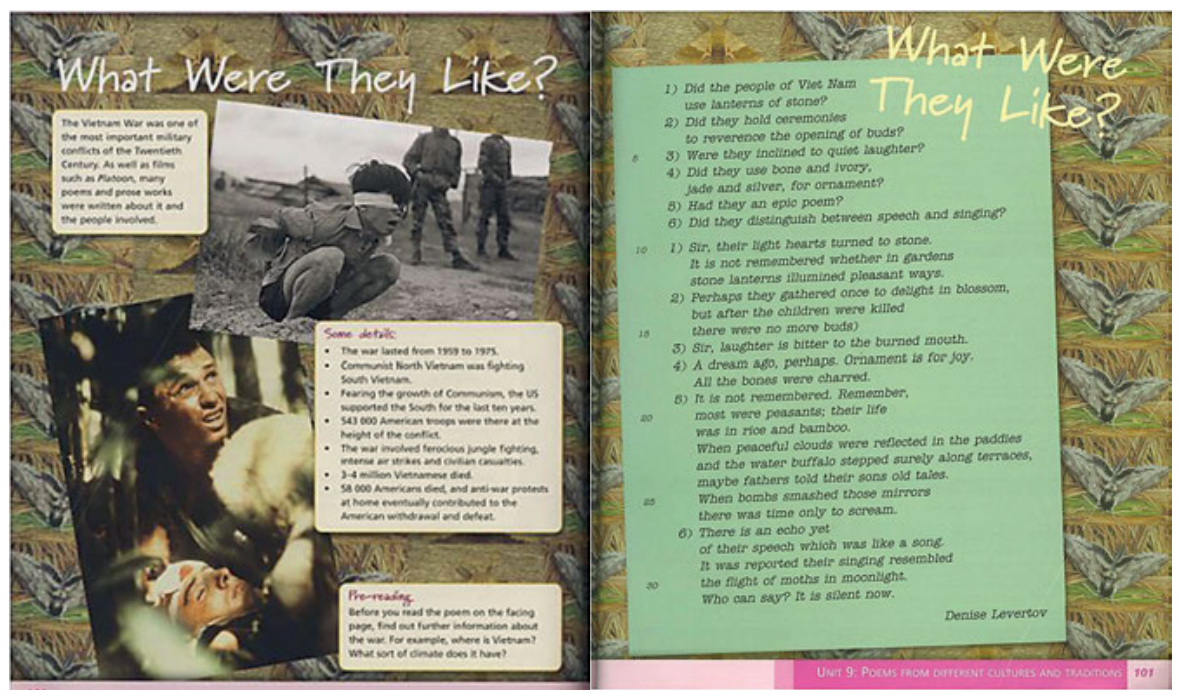

Fig. 5: Excerpt from English textbook (Brindle/Machin/Thomas 2002, 100-101) 
Figure 4 is set on a single page, using one or two columns per page (a photograph of a painting showing Blake with his family is set on a separate page). There is no background colour. In figure 5 - a response to the Vietnam War - the two-page spread is tessellated with full-colour graphic elements overprinted on a decorative background of butterflies. Like the Japanese Science textbook, it illustrates a design in which not only image but layout also has become central. Through placement, graphic designers - alongside or instead of 'authors' of writing - now articulate relations between different text elements; they integrate these elements into a coherent 'text'. On the two-page spread in the contemporary English textbook the left-hand page contains five separate textual 'chunks'. Proximity and (small) overlaps suggest connection, differently and more or less strongly. The differential use of modes suggests a division of some kind: image for two 'chunks', writing for three, potentially signifying a functional distinction. This is reiterated through the tilting of the images - opposed to the straight positioning of the blocks of writing - one suggesting casualness, the other formality; an implied ontological difference of writing and image. The layout suggests 'assemblage', bringing together different materials and representations.

The example is an 'extreme' instance of more general shifts in layout. Textbooks from the 1930s are A5-sized or smaller. Their pages are, typically, designed following a rigid grid, in a single column, with consistent margins, baselines, headers and footers, allowing the writing to flow continuously from one column to the next from top left to bottom right; it runs across pages. In the 2000s, the book is bigger, and we see a move away from the rather rigid, writing-driven grid, which was common in the 1980s. We also see an increase in the use of the two-page spread from the 1980s, providing an entirely different 'canvas' or 'site of display'. Most textbooks now use varying numbers of columns per page and varying column widths, allowing writing to be aligned with often irregularly shaped images. Writing may still be running across pages but more often page breaks coincide with separations of different parts of the text, marked off by line boxes and background colours.

The examples also show that while in 1934 layout was the semiotic work of an 'author'; it is now the work of the graphic designer. As layout moves from the domain of the author to the domain of the graphic designer it is used to produce different, less fixed, forms of composition and cohesion; or a form of cohesion which operates differently, at a higher more abstract level, an image-like unifying feature. This has profound implications for the reader. For instance, the contemporary English textbook, as well as the Japanese science textbook, provide a multiplicity of 'entry' and 'exit' points, or navigation paths, as opposed to textbooks where the order in which learners engage with various parts of the text is fixed in and by writing. The new compositional arrangements place different demands on the learner. When pathways connections between different 'chunks' of text - are less fixed, readers are much more left to produce coherence for themselves.

In the examples, readers are not only left to construct connections at the level of different textual elements, they are also left to make connections within written 
textual elements. Compare the following two excerpts, from the 1934 and 2002 English textbooks:

\section{Excerpt 4 (Mamour 1934, 89)}

The Elizabethan age was succeeded by a period of religious and political strife, which culminated in the triumph of Puritanism under Oliver Cromwell. Therefore the expansive development of literature was restricted, and thought mainly concentrated on one particular book-the Bible. The dominating figure of this age is John Milton, the great Puritan poet ; but he is so supremely an artist that he blends the perfection of ancient art, as learnt from the Renaissance, with the religious turmoil of his time, which has so profound an effect on his work. His most famous poem is the epic Paradise Lost, which relates the story of 'man's first disobedience and its fruit.' He also wrote many shorter poems, of which the following is an example.

\section{Excerpt 5 (Brindle/Machin/Thomas 2002, 100-101)}

The Vietnam War was one of the most important military conflicts of the Twentieth Century. As well as films such as Platoon, many poems and prose works were written about it and the people involved.

Some details:

The war lasted from 1959 to 1975.

Communist North Vietnam was fighting South Vietnam.

Fearing the growth of Communism, the US supported the South for the last ten years.

543000 American troops were there at the height of the conflict.

The war involved ferocious jungle fighting, intense air strikes and civilian casualties.

3-4 million Vietnamese died.

58000 Americans died, and anti-war protests at home eventually contributed to the American withdrawal and defeat.

As well as a reduction in the number of clauses per sentence (13 clauses in 5 sentences in Excerpt 4 and 13 clauses in 10 sentences in Excerpt 5) and a reduction in hypotaxis (non-restrictive relative clauses introduced by 'which'), which we also observed in Science textbooks, these examples show a reduction in the number and range of different semantic relations between the clauses: the 1934 excerpt has Causals ('therefore'), Additives ('and'), Contrastives ('but'), and Elaborations ('which'); the 2002 excerpt has Causals (adverbial phrase of cause), and Additives ('and'). As a result, the two examples project different kinds of readers. The 1934 excerpt 'spells out' all that needs to be known and/or learnt; the 2002 excerpt 'outlines', and 'highlights', leaving it to the reader to 'fill in', accepting that different readers will fill in differently. Indeed, the writing points to the same shift in agency as the layout does, leaving it to the reader (and their teachers) to draw connections that were previously made for them. Perhaps it is this shift in agency that the current social-political climate in England attempts to guard against, so that designs such as the 2002 example remain 'radical' still, and as yet atypical, while an equivalent of the Japanese Science text has yet to be published for the English textbook market. 


\subsubsection{Typography}

We conclude our account of changes in textbooks with a discussion of typography. Variation in typeface has increased significantly, suggesting that designers have more choice now than before. This produces new potentials for meaning making. Until the late 1980s usually one font was used consistently throughout a textbook; typically, in textbooks from the 2000s, different fonts are used for different parts of the text. From the late 1980s, typeface is used to separate out different curricular and pedagogic entities. Further, designers now use the meaning potentials of typeface to suggest meanings of different entities: the literary 'feel' of serif is used for poems, handwritten font to represent annotations as 'notes', as provisional, spontaneous, unpolished. Instructions or exercises may be set in sans serif, suggesting they are transparent, straightforward and unambiguous. Indentation is in decline; boxing and/or background colouring are now common features. These mark boundaries between parts of the text sharply, suggesting that they operate as separate entities. The shift from indentation to boxing/colouring points to a modal change: written elements are increasingly acting like graphic entities, themselves connected not through cohesive devices of writing but through the layout of the page, as discussed above.

Take the following examples from English textbooks. The two differ typographically and in layout. In one textbook (Heath et al. 1986), poem and 'materials' are clearly separate, as 'main item' and 'technical resource'. In the other textbook (Baker/Constant/Kitchen 2003), poem and supplementary materials are integrated, using leader lines to connect the 'annotations' to parts of the poem. The 1986 excerpt uses bolding to highlight 'difficult words', glossed in a separate text box. The poem is placed in a different colour to that framing the pedagogic materials.

The 1986 excerpt presents the poem as separate, with a literary and pedagogic 'apparatus' to be used as a resource. The 2003 excerpt presents the poem with several layers of meanings super-posed, doing semiotic work, which in the other is left to the reader. In the 1986 excerpt only line numbers are added to the poem; in the 2003 excerpt the poem is fully drawn into a pedagogic framing: it has become a pedagogic rather than a literary object. We might hypothesize that the designers of the 2003 excerpt envisage learners as unwilling or unable to engage with the poem in its 'pure' form; alternatively we might assume that the designers treat the 'poem' as a pedagogic object, as text-material for a specific pedagogic purpose, not immediately for its poetic characteristics. Engagement and pedagogic relations with a pedagogic object and an aesthetic one are very different. This resonates with our observation about Science textbooks, in which pedagogic and curricular tasks are now foregrounded. 


\subsection{Digital Learning Platforms}

We noted in our introduction that the textbook is now one of a range of different learning platforms used by students. (We note in passing that the term platform seems quite recent in this use. We would not have expected, some 20 years ago, to have written, for instance, 'the platform of the book provides potentials not found with other platforms'.) Not only are there more and different platforms, the relations between them has also changed. Where previously 'reference books' and 'information books' designed for the school curriculum and beyond were used in conjunction with textbooks, in the 1990s CD-ROMs were sometimes added, giving students access to some additional digital resources. Now a wide range of 'resources', e.g. videos, apps, wikis is readily available, with the potential to take over some of the curricular functions previously served by textbooks alone. Indeed the position of the school textbook as the dominant site of learning and knowledge (re)production has changed. Contemporary students move rapidly in and out of learning platforms that are entirely differently designed, with different sets of modes and media, and different pedagogic relations. That is now beginning to be acknowledged in textbooks: for instance, a recently published textbook (Askey et al. 2014) suggests for each 'lesson' what phrase to key into an internet search box 'to find out more'.

To understand the role of the textbook in this newly emerging, multi-sited environment for young people we need to explore exactly how these new learning platforms are different from and connect with textbooks. Take the following example, drawn from lgfl.skoool.co.uk. It is a lesson that addresses a curriculum entity for Key Stage 3 Maths: 'rotational transformations'. In the lesson a demonstration is given of how to rotate an angle using a compass, ruler and protractor. The example illustrates one affordance of digital platforms: their potential and actual use of speech and moving image alongside image, writing, layout and typography.

The 'lesson' consists of 8 'scenes' that unfold in sequence as a slideshow. Users can pause the slideshow at any time, and move back and forth between slides by clicking on the relevant buttons. Each slide has a (moving) image at the centre of the slide, superimposed on grid paper. At the bottom of the slide, below the image, a written element is placed, indeed as 'caption', of 2-3 sentences. As a slide first appears, a spoken text by a 'voice-over' is played, as is the moving image. 


\subsubsection{Writing and Speech}

Scene 4 of the slideshow shows the following written text:

Put pointer of compass on point 'a'. Open out compass to length of 'ac'. Draw a curve which passes through ' $c$ '. This ensures that the length of the lines in the image will be the same as in the original triangle. This makes sure that the length of 'ac' (the image) is the same as 'ac' (the original) because the size of an object doesn't change during rotation.

Lexically, the spoken text parallels this written text. Yet if we analyse them in more detail, we see that each provides distinct learning environments. In speech, intonation draws attention to elements with major pitch movement, here to object involved 'compass'; to location - 'point a'; to extent of action - 'out'; etc. In writing, syntax is used to draw attention to the first-mentioned elements - action to be performed: put, open out, draw; and to imperative mood, which foregrounds action as command. In this contrapuntal organization, writing highlights 'action-as-commands' - put, open out, draw; and speech highlights 'objects and attendant circumstances' - location, shape.

\subsubsection{Moving Image}

Figure 6 shows a still from the moving image used in the mathematics lesson. In moving image, action unfolds in time: moving image has a spatial and a temporal organization.

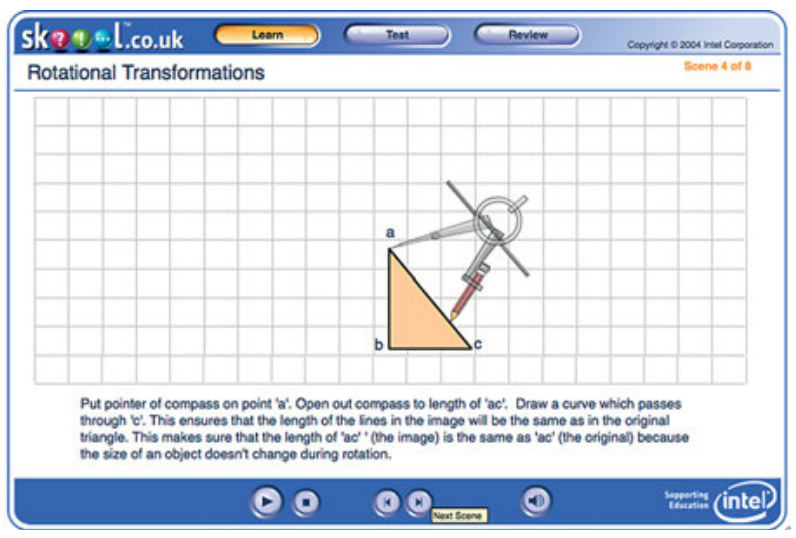

Fig. 6: Snapshot from Mathematics learning resource (lgfl.skoool.co.uk)

This brings distinct increases in semiotic possibility. Elements can now appear and disappear so that movement can be suggested. In the scene referred to here, the 
triangle is the first element to appear; the compass then appears, with its pointer at 'A'. There is the 'opening out' of the compass and the inscription of a curve; the compass then disappears. Moving image represents the demonstration of how to use a compass differently from the written and spoken text-elements: it is specific about what 'opening out' is and what 'drawing a curve' entails: a movement of the compass whereby one of its legs, A, retains its position while the other leg $\mathrm{C}$, which leaves a trace, makes a clockwise turn.

The producers of the slideshow use the affordances of the digital platform to pace text elements in ways that textbook designers can't: the speed with which elements unfold in time is set by the designers, not by the users; the latter can pause, replay and move from one slide to another as they please, but within each slide, the moving image and the spoken text cannot be controlled.

Similar usage of moving image can be found in videos on Youtube, (where, of course, often no reference is made to the English National Curriculum - whereas the 'rotational transformations' example did). For instance, a video on 'digestion' (http:// www.youtube.com/watch?v=P5lyQUtq1KQ) uses image to visualize processes and show objects from different angles, while a 'narrator' speaks, naming objects and processes. Writing is used for 'headings' marking the boundaries between different 'chunks' or clips. As it is played, as with the animated demonstration of how to rotate an angle, it provides a temporal, sequentially fixed ordering and pacing, unlike the image-dominated textbook, giving more control to the producers.

\subsubsection{Dynamic Image}

Other examples illustrate further representational changes still. Screens not only allow for image to be moving, they also allow it to be 'dynamic'. By that we mean images that are jointly 'settled' by 'authors', as in still and moving image, and by 'readers'; readers can manipulate image by setting parameters pre-selected by the authors. The parameters can be set -'activated'- by touching the keyboard, mouse, or screen. For instance, ISOForm (www.iso-form.com) has published iPad apps on human anatomy that allow 'readers' to adjust scale and angle, enabling them to zoom in and out and rotate representations of organs such as the liver around their imagined centrepoint. Through these 'interactive' features (Adami 2013) the dynamic image distributes semiotic work differently over 'producer' and 'user' than the moving image.

The example of dynamic image that we referred to is designed for doctors and patients, not for students, i.e., for an institution that produces a different 'curriculum' than the National Curriculum. Yet our point is that these alternative resources, with their distinct multimodal design and pedagogic potential, are now readily available to students and teachers, often for free, who use them alongside the textbook. One major task for future research is to produce accounts of these new constellations of learning platforms in which students operate today. In this chapter, we have shown 
how Social Semiotics and multimodal studies more generally can contribute to that account, highlighting the social significance of changes in text making.

\section{Conclusions}

We have demonstrated that typography, image, writing and layout contribute to meaning in text in ways significant for social relations within and across its makers and users. In textbooks, typography and image are used to construct and differentiate between different imagined abilities as much as writing does (cf. highlighting words which are assumed to be 'difficult' for certain potential readers; using 'abstract' representations of an electric circuit for 'advanced' readers). This has important implications for researching and evaluating textbooks and text more widely: Text designed for readers to engage with aspects of the world cannot be fully understood without due attention to all modes operating in that text.

The use of typography, image, writing and layout has changed between 1930 and now. Writing contains fewer complex sentences and more active voice, and has moved towards more instruction and pedagogic framing. There are more images now, including images used as fully, equally complementary to writing, for instance diagrams also found in Science outside school, such as electric circuits. Typography is more varied, providing new means of differentiating between different audiences. Layout is now a major resource for constructing text, loosely connecting but not fixing parts of the text through their arrangement on a 'two-page spread', which were previously held together by cohesive devices in writing.

For producers of textbooks the changes in design suggest a shift in their social/ pedagogic relations, for instance where the graphic designer now takes responsibility for layout, which was previously the domain of the author. For 'users' of textbooks the changes in design demand new forms of semiotic work: a fluency not only in 'reading' writing, image, typography and layout jointly, but an understanding of the overall design of a multimodal text. The changes in the design of textbooks also convey major shifts in pedagogic relations between 'producers' (as initial makers) and 'users' (as interpreters, 'text re-makers'); for instance, where previously reading paths were fixed by authors, increasingly this is now left to readers to establish these or not according to their interests.

This shift in the distribution of semiotic work is tied in with contemporary social allocations of agency, forms of (collaborative) authorship, themselves linked to a move away from traditional understandings of 'knowledge'. Yet we also noted what appears to be the current boundary of these developments. Designs in which image is dominant, as in the English textbook excerpt about the Vietnam war, are still rare, and the Japanese image led Science textbook design is still 'unheard of' in the English context. This stands in sharp contrast with 'information' platforms outside the official 
curriculum, where image has been central for at least 30 years (cf., for instance, the Dorling and Kindersley publications from the 1980s, e.g. Macaulay 1988).

Our social semiotic account of the changes in textbooks warns against old ideological assumptions about associations between representational, epistemological and cognitive complexity. We do not see the reduction in, say, syntactic complexity of writing, or the increase in the use and expansion of the functions of image in textbooks as evidence of 'dumbing down', or of a reduction in the cognitive demands that students face. Instead our guiding question is: What kinds of complexity are there? Where do these lie? What are the features and characteristics of 'complexity'? What kinds of semiotic work are being done, by and for whom?

Seen from that perspective, there are gains and losses. Lost are certain forms of written complexity, stability, canonicity and vertical power structures. Gained are 'horizontal', more open, participatory relations in the production of knowledge, blurring former distinctions within and across production and consumption, writing and reading, and teaching and learning. We do not want to claim that the gains and losses we have identified are 'positive' or 'negative', nor do we dismiss such claims made by others. We believe that both gains and losses need to be attended to and understood by all those who wish to understand contemporary text making, regardless of one's evaluative framework.

\section{References}

Adami, Elisabetta (2013): A social semiotic multimodal analysis framework for website interactivity. In: NCRM Working Paper 2/13. Retrieved from http://eprints.ncrm.ac.uk/3074/4/website_ interactivity_Adami.pdf

Ambrose, Gavin/Paul Arthur Harris (2005): Layout. Lausanne.

Askey, Sarah et al. (2014): Key Stage 3 Science. Student Book 1. London.

Baker, Jill/Clare Constant/David Kitchen (2003): Access English 3. Oxford.

Barthes, Roland (1977[1964]): Image, Music, Text. London.

Bernstein, Basil (1996): Pedagogy, Symbolic Control and Identity. Theory, Research, Critique. London.

Bezemer, Jeff/Gunther Kress (2008): Writing in multimodal texts. A social semiotic account of designs for learning. In: Written Communication 25 (2), 166-195.

Bezemer, Jeff/Gunther Kress (2009): Visualizing English. A social semiotic history of a school subject. In: Visual Communication 8, 247-262.

Brindle, Keith/Roger Machin/Peter Thomas (2002): Folens GCSE English for AQA/A. Dunstable. Burn, Andrew (2009): Making New Media. Creative Production and Digital Literacies. New York. Chapman, Carol/Moira Sheehan (2003): Catalyst. 1G. A Framework for Success. Oxford.

Cope, Bill/Mary Kalantzis (2009): Multiliteracies. New literacies, new learning. In: Pedagogies 4 (3), 164-195.

Fairbrother, F./E. Nightingale/F.J. Wyeth (1935): General Science. Part III. London.

Field, T.H.J. (1937): Elementary General Science. Book 1. London.

Halliday, Michael (1967): Intonation and Grammar in British English. The Hague. 
Halliday, Michael (1985): An Introduction to Functional Grammar. London.

Haslam, Andrew (2006): Book Design. London.

Heath, R.B. et al. (1986): Longman English 1. Burnt Mill, Harlow.

Hill, Graham/John Holman (1986): Science 1. Walton-on-Thames.

Hodge, Robert/Gunther Kress (1988): Social Semiotics. Cambridge.

Jewitt, Carey (2006): Technology, Literacy and Learning. A Multimodal Approach. London.

Jewitt, Carey/Jeff Bezemer/Ken Jones/Gunther Kress (2009): Changing English? The impact of technology and policy on a school subject in the $21^{\text {st }}$ century. In: English Teaching: Practice and Critique 8/3, 8-20.

Klug, Nina-Maria/Hartmut Stöckl (2015): Sprache im multimodalen Kontext. In: Ekkehard Felder/ Andreas Gardt (Hg.): Handbuch Sprache und Wissen. (Handbücher Sprachwissen - HSW, Bd. 1). Berlin/Boston, 242-264.

Kress, Gunther (2010). Multimodality. A Social Semiotic Approach to Contemporary Communication. London.

Kress, Gunther (2014): What is mode? In: Carey Jewitt (ed.): Handbook of Multimodal Analysis. 2nd ed. London, 60-75.

Kress, Gunther et al. (2001): Multimodal Teaching and Learning. The Rhetorics of the Science Classroom. London.

Kress, Gunther et al. (2005): English in Urban Classrooms. Multimodal Perspectives on Teaching and Learning. London.

Kress, Gunther/Theo van Leeuwen (2006): Reading Images. The Grammar of Visual Design. London. Macaulay, David (1988): The Way Things Work. London.

Mamour, A. (1934): The Complete English. Book II. London.

Martinec, Radan/Andrew Salway (2005): A System for image-text relations in new (and old) media. In: Visual Communication 4 (3), 337-371.

Mavers, Diane (2011): Children's Drawing and Writing. The Remarkable in the Unremarkable. London.

New London Group (1996): A pedagogy of multiliteracies. Designing social futures. In: Harvard Educational Review 66, 60-92.

Publisher's Association (2013): The PA Statistics Yearbook 2012. London.

Science Education Group (2002): Salters GCSE Science Y10. Oxford.

Shoseki Books (2008): Science Year Two. Shoseki, Tokyo.

Stöckl, Hartmunt (2005): Typography. Body and dress of a text - A signing mode between language and image. In: Visual Communication 4 (2), 204-214.

Stray, Chris (1994): Paradigms regained. Towards a historical sociology of the textbook. In: Journal of Curriculum Studies 26 (1), 1-29.

Unsworth, Len (2001): Teaching Multiliteracies across the Curriculum. Changing Contexts of Text and Image in Classroom Practice. Buckingham.

Yandell, John (2013): The Social Construction of Meaning. Reading Literature in Urban English classrooms. London. 